\title{
INFLUENCE OF MOISTURE CONTENT ON THE WAVE VELOCITY TO ESTIMATE THE MECHANICAL PROPERTIES OF LARGE CROSS-SECTION PIECES FOR STRUCTURAL USE OF SCOTS PINE FROM SPAIN
}

\author{
M.J. Montero ${ }^{1}$, J. de la Mata ${ }^{1}$, M. Esteban ${ }^{1, \wedge}$, E. Hermoso $^{2}$
}

\begin{abstract}
The aim of this research is to evaluate the influence of the moisture content of wood on stress wave velocity, as a nondestructive technique for estimating the mechanical properties of gross cross-section Spanish Scots pine (Pinus sylvestris) lumber for structural use. 26100 x 150 x $3000 \mathrm{~mm}$ pieces from Segovia, Spain, were tested with different moisture content values, from 35,5 to $9 \%$. Measurements of longitudinal stress wave velocity were carried out during the natural drying process by using three commercial portable devices based on ultrasonic, acoustic and vibrational techniques. The results can be summarized as three percentage points of decreasing velocity per percentage point of increased wood moisture content in the range from 11,8 to $21,4 \%: 0,48 \%$ for ultrasonic, $0,50 \%$ for acoustic wave and $0,65 \%$ for longitudinal vibration.
\end{abstract}

Keywords: Mechanical properties, moisture content, nondestructive techniques, Pinus sylvestris.

\section{INTRODUCTION}

Nondestructive techniques are widely used in several fields of technology to estimate the properties of materials. Some of these technologies are wave-based and have been successfully used in recent decades to estimate the mechanical properties of wood. Interest in these applications and the need for reliable estimations are increasing, in order to guarantee the safety and improve the efficiency of timber structures. One of the main fields in which these technologies need to be improved concerns the influence of certain parameters such as the moisture content of wood.

The aim of this work is to improve the accuracy of the estimation of the mechanical properties of wood based on stress wave techniques applied to pieces of gross cross-section Spanish Scots pine. For this purpose, 26 timber pieces with nominal dimensions $100 \times 150 \times 3000 \mathrm{~mm}$ were tested with different moisture content values, from 35,5 to $9,0 \%$, and measurements of longitudinal stress wave velocity were carried out during the natural drying process by using three commercial portable devices based on ultrasonic, acoustic and vibrational techniques. The results of this work make it possible to estimate the mechanical properties of wood under different conditions of moisture content, such as freshly sawn pieces, timber structures in existing buildings or timber pieces during quality control.

\footnotetext{
Department of Construction and Rural Roads. Technical University of Madrid, Timber Construction Research Group, ETSI Montes,

Ciudad Universitaria s/n, 28040 Madrid, Spain.

${ }^{2}$ Forest Research Centre (CIFOR-INIA), Wood Technology, P.O. Box 8111, 28080 Madrid, Spain.

• Corresponding autor: miguel.esteban@upm.es

Received: 27.02.2014 Accepted: 22.08.2014
} 


\section{Wood and moisture content}

The effects of moisture content (MC) on the physical and mechanical properties of wood, which is a hygroscopic material, have been studied in depth. Some of the physical and mechanical properties of wood such as density, strength and elasticity are strongly dependent on water content (Simpson and Wang 2001). The main aim of this paper is to evaluate the influence of the moisture content of the wood on the stiffness (MOE) of the timber pieces.

The main influence of moisture content on the physical and mechanical properties of timber is shown when the moisture content is below the fiber saturation point (FSP), which corresponds to a MC close to $30 \%$ for all species of timber. A MC above the FSP means that microscopic vacant spaces contain free water (Oliveira et al. 2005). On the other hand, the timber in existing constructions and timber supplied by sawmills is conditioned by environmental temperature and relative humidity factors, which means that the final $\mathrm{MC}$ is substantially lower than $30 \%$. This is why most of studies of the influence of the moisture content of wood on its physical and mechanical properties cite values lower than $30 \%$.

\section{Nondestructive wave-based techniques}

One of the most common nondestructive techniques used by industry and many other applications, not only for timber, is based on the relationship between the velocity of propagation of a wave through the material (v), the dynamic modulus of elasticity (Ed) and density ( $\rho$ ). This relationship has an elementary physical basis, is valid for any kind of mechanical wave and takes the general form of equation 1:

$$
E_{d}=v^{2} \cdot \rho
$$

Several wave-based techniques have been developed during recent decades. The main difference between these techniques consists of the frequency of the wave and the way in which it is generated and detected. Research has focused on rapid and efficient evaluation methods such as ultrasonic, acoustic or stress waves and vibration (Wang and Ross 2002, Cui et al. 2005).

Strong relationships were observed between dynamic modulus of elasticity $\left(\mathrm{E}_{\mathrm{d}}\right)$, static modulus of elasticity (MOE) and other mechanical properties such as strength or modulus of rupture (MOR). Some analyses revealed strong correlation coefficients between dynamic modulus of elasticity and static properties for specimens of $25 \times 25 \times 406 \mathrm{~mm}$ nominal size, obtained from Western hemlock and Sitka spruce woods: 0,91 for MOE and 0,68 for MOR, with the two species combined (Wang et al. 2000).

Many other parameters can be included on the process of wave analysis, including the moisture content of the wood, its dimensions, and the knot ratio of the pieces or slope of grain, among others. The aim of these parameters is to estimate mechanical properties as accurately as possible.

The application of these techniques to timber has been studied by several research groups in Europe and around the world. Some research groups have studied Spanish timber species during the last decades (Arriaga et al. 2005, Arriaga et al. 2006, Hermoso et al. 2007, Esteban et al. 2007).

\section{Stress waves}

One of the most widespread and accurate nondestructive techniques used to study timber is based on stress waves. These techniques are based on the observed relations between the propagation of a wave thorough a piece (velocity and attenuation) with some of the properties of the material (mechanical and physical properties), as well as some characteristics or singularities of the piece as decays, holes or other irregularities (Ross and Pellerin 1994). 
There are several techniques based on waves, the main difference is the frequency of the wave and, depending on the devices, the way in which the wave is generated and registered. The most commonly range of frequency used on structural timber pieces goes from a low value of any hundred $\mathrm{Hz}$ (acoustic or stress waves in general) to 30000 to $50000 \mathrm{~Hz}$ (ultrasound waves). Some of the most relevant cases of stress wave studies on timber are cited below. All these techniques are based on the relations between the acoustic performance of the material and its stiffness.

This is the case of the study carried out for large cross-section spruce, in which mechanical properties were estimated from the longitudinal propagation velocity of an ultrasonic wave, with a coefficient of determination $\left(\mathrm{R}^{2}\right)$ value in the range of 0,66 to 0,83 (Sandoz 1989, Sandoz 1993). For Spanish large cross-section pieces of coniferous timber for structural use, values of $\mathrm{R}^{2}$ in the range of 0,74 for the static modulus of elasticity and 0,60 for strength are cited (Íñiguez 2007).

Regarding the influence of the moisture content of wood on ultrasonic wave velocity, some studies cited below suggest a constant ratio, depending on the species, according to which the longitudinal propagation velocity of the wave is reduced by increasing moisture.

Many studies show a small increase in velocity while the timber is dried from values of MC higher than FSP (MC $>30 \%$ ) to the FSP reference value (MC $30 \%$ ) (Sakai 1990, Mishiro 1995, Simpson and Wang 2001, Bucur 2006).

However, a strong increase in velocity is evident when timber is dried from FSP to lower MC values or dryness (Wang and Chuang 2000). Pieces of spruce wood therefore showed a $0,8 \%$ drop in propagation velocity for each percentage point of moisture content increase, at values from 30\% to 5\% (Sandoz 1989).

Likewise, when moisture content increases, ultrasound velocity not only decreases but also attenuation increases. The maximum values of velocity and the minimum values of attenuation were measured in dry conditions (Oliveira et al. 2005).

In other research works, longitudinal ultrasound wave propagation velocity shows a decrease of 23,6 $\mathrm{m} / \mathrm{s}$ for each percentage point increase in the moisture content of goupia wood (Goupia glabra) and 25,4 $\mathrm{m} / \mathrm{s}$ increase in Brazilian pine wood (Araucaria angustifolia), for moisture content values from the point of saturation of the fiber to oven dry condition (Gonçalves and Leme da Costa 2008).

Similar research was carried out by testing 30 spruce wood pieces under two values of moisture content ( $14 \%$ and $22 \%)$. An empirical coefficient for the decrease in velocity of approximately $0,8 \%$ was obtained for a $1 \%$ increase in $\mathrm{MC}$ and for a variation of moisture contained in the extrapolated range from $5 \%$ to $30 \%$ (Sandoz 1989).

Several studies have shown the influence of moisture content on the velocity of sound propagation. A significant increase in wave velocity is produced as the moisture content of wood decrease (Ross and Pellerin 1991, Simpson and Wang 2001, Kang and Booker 2002). 


\section{Vibration}

Another technique based on similar fundaments consists of analysis of the natural frequency of vibration as an important elastic property of the wood. Different vibration modes can be generated, as longitudinal, transversal (in bending) or torsion, and different way to be generated can be applied (Görlacher 1990). In case of longitudinal waves, the first harmonic or the fundamental frequency corresponds to one-half wavelength which fits in the length of the piece. In this situation, according to the principles of physics and waves, wave velocity must be calculated according to the equation 2 .

$$
v=\lambda \cdot f=2 \cdot L \cdot f_{1}
$$

Where, $v(\mathrm{~m} / \mathrm{s})$ is the velocity, $\lambda(\mathrm{m})$ is the wavelength, $f(\mathrm{~Hz})$ is the frequency, $L(\mathrm{~m})$ is the length of the piece and $f_{l}(\mathrm{~Hz})$ is the fundamental frequency corresponding to the first mode of vibration or first harmonic in longitudinal.

For Spanish structural large cross-section softwood, the MOE can be estimated by means of the dynamic modulus of elasticity $\left(E_{d}\right)$ obtained from the velocity of vibration with a 0,76 coefficient of determination $\left(\mathrm{R}^{2}\right)$. In the estimation of MOR from the dynamic MOE, a coefficient of determination of 0,65 is achieved (Íñiguez 2007).

In another study, a high coefficient of determination $\left(\mathrm{R}^{2}=0,89\right)$ was obtained by comparing static and dynamic MOE using the technique of transverse vibrations. The work was conducted on 3050 x $110 \times 3000$ $\mathrm{mm}$ pieces of cupiuba wood (Sales et al. 2011).

Another study of poplar wood (Populus $x$ euramericana) compared the dynamic variables of logs with static variables of small clear specimens $(20 \times 20 \times 30 \mathrm{~mm})$ taken from the same log. A strong correlation coefficient $\left(\mathrm{R}^{2}=0,81\right)$ was obtained between the dynamic MOE based on log resonance vibration and the MOE of the small clear specimens taken from the same logs (Yin et al. 2011).

Regarding the moisture content of wood and the dynamic MOE, a study of spruce pieces with a length of $4500 \mathrm{~mm}$ and different widths $(202 \mathrm{~mm}$ and $98 \mathrm{~mm}$ ) and thicknesses $(49 \mathrm{~mm}$ and $41 \mathrm{~mm}$ ) was carried out by measuring the vibration velocity during the drying process from green wood to equilibrium moisture content. An increase in vibration velocity and the dynamic MOE is produced as the moisture content of the pieces falls (Unterwieser and Schickhofer 2011).

Similar studies of the effect of temperature on the stiffness estimated from vibrational techniques were carried out on pieces of radiate pine with constant moisture content (12\%). This analysis concludes that a $20 \%$ decrease in stiffness is observed in a range of temperature from $10^{\circ} \mathrm{C}$ to $100^{\circ} \mathrm{C}$ (Cornejo and Baettig 2009).

\section{MATERIAL AND METHODOLGY}

The general methodology of this study is based on different measurements of stress wave velocity (ultrasonic, acoustic and vibration) in the timber pieces during the natural drying process.

\section{Test material}

The test material consisted of 26 sawn timber pieces of Scots pine (Pinus sylvestris L.) from El Espinar, Segovia, Spain, with nominal dimensions of $3000 \times 150 \times 100 \mathrm{~mm}$. The source of the sample is one of the most representative forest areas and providers of structural timber in Spain. Green specimens were selected at the sawmill, ensuring the greatest possible homogeneity based on MEG specifications of visual quality (UNE 56544 standard). 
Once the sample had been selected and collected, the specimens were dried naturally in a covered and enclosed environment, properly stacked and timber battened to promote uniform drying. The range of the MC of the studied timber pieces runs from 35,5 to $9 \%$. The upper value corresponds to the mean value obtained at the moment at which recently sawn pieces were collected in the laboratory. The lower figure corresponds to the mean value obtained 290 days later, when the timber reached a conditioned $\mathrm{MC}$ value corresponding to the temperature and relative humidity of the laboratory. The relative humidity during the process ranged from $30,8 \%$ to $54,5 \%$, with a mean value of $39,4 \%$, while the temperature ranged from 8,8 to $28,6{ }^{\circ} \mathrm{C}$ with a mean value of $19,3{ }^{\circ} \mathrm{C}$.

\section{Test devices}

The moisture content of the wood was measured by a Gann Hydromette HTR 300 using electrical resistance according to the EN 13183-2: 2002 standard. This equipment consists of two electrodes nailed into the timber to measure the electrical resistance of the wood and the corresponding moisture content.

To obtain the ultrasonic longitudinal wave propagation velocity Sylvatest Trio equipment was used. This device is manufactured by Concept Bois Structure, Switzerland, and is based on a $22 \mathrm{kHz}$ frequency wave and consists of two piezoelectric transducers. The time it takes the wave to pass between the two transducers is used for propagation velocity measurement. A second set of pulses is evaluated to determine the maximum energy of the received wave. It should be considered that the use of pre-drilled contact holes is recommended for improved accuracy and reliability.

A Fakopp Microsecond Timer (MST) manufactured by Fakopp, Hungary, was used to measure the flight time of an acoustic wave generated mechanically. The wave is induced by tapping the start sensor with a hammer, and it then travels in a straight line to the opposite sensor. The generated signal corresponds to a range of frequencies depending mainly on the mass and material of the hammer and the dimensions of the piece. The transducers respond to a resonance frequency of $23 \mathrm{kHz}$, the MST electronics is sensitive in the frequency range of 0,5 to $15 \mathrm{kHz}$ and the typical longitudinal frequency range of the timber pieces is 0,5 to $5 \mathrm{kHz}$. Pre-drilled contact holes are not necessary because the transducers are mounted directly on metal spikes, which provide direct contact points when the hammer is used to hit the transducers into the specimen.

The Fakkop Portable Lumber Grader (PLG) was used to determine the natural longitudinal vibration frequency of the tested lumber. Piece vibration is generated with a hammer and the signal is recorded by a microphone. The acoustic signal is analyzed by the Fourier transform to detect the natural frequency. This equipment includes a balance to determine the weight of the pieces.

\section{Methodology}

The pieces were kept in the laboratory in order to allow the different measurements with the different devices during the approximately 10 months that it took them to dry.

Moisture content was measured in the central section of the pieces according to the UNE-EN 131832: 2002 standard. At the same time, the dimensions of the cross section and the weight of the pieces were measured. The decrease of the cross-section due to shrinkage during the drying process was recorded and taken into account to calculate de volume of the pieces. 
To use the Sylvatest Trio device two $5 \mathrm{~mm}$ diameter holes were made at the heads of each piece to hold the transducers, ensuring good contact with the timber according to the manufacturer's instructions. Two longitudinal measurements of flight-time for each equipment and piece were carried out, as can be seen on figure 1 . Wave velocity was calculated according to the length of the pieces and the mean value was taken into account.

(a)
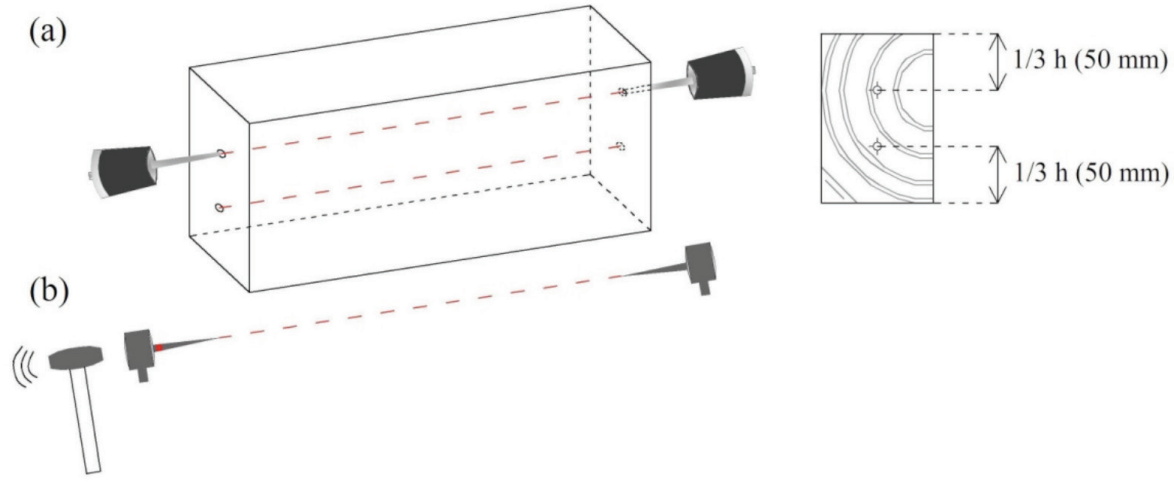

Figure 1. Ultrasonic (a) and stress wave (b) tests (de la Mata 2011).

To detect the natural frequency of longitudinal vibration in the Portable Lumber Grader equipment, vibration was generated by hammer impact on the opposite end to where the microphone was located (Figure 2). The balance included in this device was the one used to obtain the weight of the pieces. The sound signal was processed using the Fast Fourier Transform (FFT) and the longitudinal vibration frequency was obtained. The velocity of the vibration wave was calculated according to equation1.

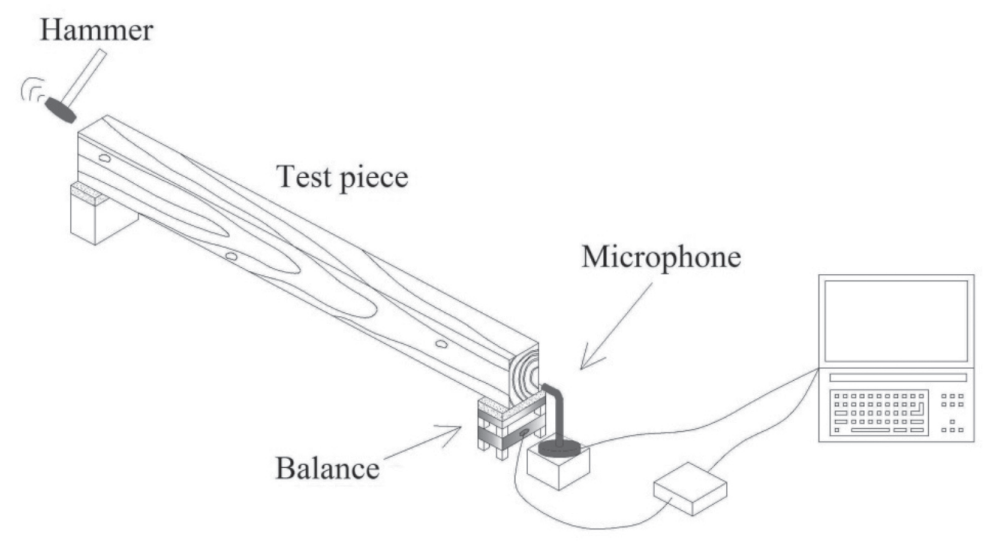

Figure 2. Test with Portable Lumber Grader equipment (de la Mata 2011).

Finally, the parameters collected make it possible to calculate the velocity and density needed in order to calculate the dynamic MOE according to equation 3.

$$
E_{d}=\rho \cdot v^{2} \cdot 10^{-6} \mathrm{MPa}
$$

Where $E_{d}(\mathrm{MPa})$ is the dynamic MOE, $\rho\left(\mathrm{kg} / \mathrm{m}^{3}\right)$ is the density based on the mass to volume ratio and $v$ $(\mathrm{m} / \mathrm{s})$ is the wave velocity (ultrasonic, stress wave or vibration). 
The whole process was repeated on the 26 pieces for 14 times during the 10 month drying process. The first measurements taken into account in this study were carried out when the mean moisture content of the wood was $35,5 \%$, and the final ones when it stood at $9 \%$. This range corresponds to values below the FSP and a linear or quasi linear relation between the moisture content and mechanical properties of the wood is expected.

\section{RESULTS AND DISCUSSION}

As was pointed out above, samples were measured 14 times during the drying process. At the beginning of the process, wood moisture content values were very disperse and variable. After studying the distribution of moisture content values measured every day, it was decided to use the average values according to other authors (Gonçalves and Leme da Costa 2008). As can be expected, as the drying process progressed moisture content fell and there was less variability. Those values are summarized in figure 3 .

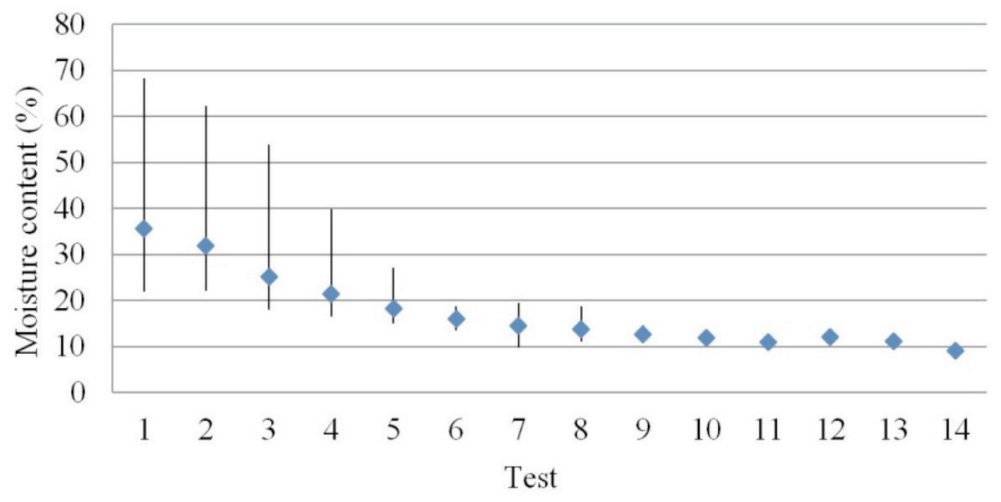

Figure 3. Average and range of moisture content values during the drying process. 
Table 1 shows the main results of the measurements carried out on the 26 samples during the drying process, as follows:

- Number of the test and measurement.

- Days elapsed since the green pieces were selected at the sawmill.

- Mean value of moisture content (MC, \%) and coefficient of variation $(\mathrm{CV}, \%)$.

- Mean value of density $\left(\rho, \mathrm{kg} / \mathrm{m}^{3}\right)$ and coefficient of variation $(\mathrm{CV}, \%)$.

- Mean value of velocity of an ultrasonic wave $\left(\mathrm{v}_{\mathrm{SYL}}, \mathrm{m} / \mathrm{s}\right)$ and coefficient of variation $(\mathrm{CV}, \%)$.

- Mean value of velocity of a stress wave ( $\left.\mathrm{v}_{\text {MST }}, \mathrm{m} / \mathrm{s}\right)$ and coefficient of variation $(\mathrm{CV}, \%)$.

- Mean value of velocity of a vibration wave $\left(\mathrm{v}_{\mathrm{PLG}}, \mathrm{m} / \mathrm{s}\right)$ and coefficient of variation $(\mathrm{CV}, \%)$.

Table 1. Values of each variable during the drying process.

\begin{tabular}{|l|l|c|c|c|c|c|c|c|c|c|c|}
\hline \multirow{2}{*}{ Test } & \multirow{2}{*}{ Days } & \multicolumn{3}{l|}{ MC $(\%)$} & \multicolumn{2}{l|}{$\rho\left(\mathrm{kg} / \mathrm{m}^{3}\right)$} & \multicolumn{2}{l|}{$\mathrm{V}_{\text {SYL }}(\mathrm{m} / \mathrm{s})$} & \multicolumn{2}{l|}{$\mathrm{V}_{\text {MST }}(\mathrm{m} / \mathrm{s})$} & \multicolumn{2}{l|}{$\mathrm{V}_{\text {PLG }}(\mathrm{m} / \mathrm{s})$} \\
\cline { 3 - 14 } & & Mean & CV\% & Mean & CV\% & Mean & CV\% & Mean & CV\% & Mean & CV\% \\
\hline 1 & 21 & 35,5 & 37,7 & 576,5 & 20,7 & 4201,1 & 7,4 & 4221,2 & 7,6 & 3929,1 & 17,5 \\
\hline 2 & 26 & 31,9 & 39,2 & 537,2 & 15,7 & 4328,4 & 6,6 & 4347,4 & 6,2 & 3915,3 & 7,1 \\
\hline 3 & 32 & 25 & 33,8 & 510,9 & 10,5 & 4468,6 & 5,2 & 4488,2 & 4,9 & 4045,3 & 5,8 \\
\hline 4 & 42 & 21,4 & 25,2 & 492,7 & 8,2 & 4544,2 & 4,3 & 4574,4 & 4,0 & 4126,5 & 5,1 \\
\hline 5 & 54 & 18,3 & 16,1 & 504,8 & 7,7 & 4630,6 & 4,2 & 4667,3 & 3,9 & 4209,6 & 5,4 \\
\hline 6 & 66 & 15,9 & 9,6 & 496,4 & 7,7 & 4692,9 & 4,1 & 4755,1 & 3,7 & 4294,6 & 5,3 \\
\hline 7 & 80 & 14,4 & 12,6 & 490 & 7,6 & 4740,3 & 4,3 & 4779,3 & 3,9 & 4339,1 & 4,9 \\
\hline 8 & 94 & 13,7 & 12,8 & 489 & 7,3 & 4746,9 & 4,3 & 4794,9 & 3,9 & 4370,9 & 4,9 \\
\hline 9 & 108 & 12,5 & 7 & 485,9 & 7,4 & 4763,7 & 4,3 & 4808,3 & 3,8 & 4394,8 & 4,9 \\
\hline 10 & 123 & 11,8 & 5,7 & 485 & 7,4 & 4764,4 & 4,5 & 4808,4 & 3,9 & 4399,4 & 4,8 \\
\hline 11 & 137 & 11 & 6,1 & 482,1 & 7,4 & 4782 & 4,3 & 4800,5 & 3,8 & 4405,1 & 4,8 \\
\hline 12 & 158 & 12 & 7,3 & 495,4 & 7,4 & 4791,9 & 4,2 & 4805 & 3,9 & 4421,6 & 4,8 \\
\hline 13 & 213 & 11,1 & 7,2 & 494,1 & 7,5 & 4786,1 & 4,4 & 4823,1 & 3,9 & 4435,6 & 4,8 \\
\hline 14 & 290 & 9 & 7,2 & 488,3 & 7,7 & 4938,7 & 4,1 & 4952,9 & 3,9 & 4524,4 & 4,8 \\
\hline
\end{tabular}

The nominal dimensions of the pieces selected at the sawmill were $100 \times 150 \mathrm{~mm}$. The dimensions measured in the laboratory of the planed green pieces gave an average value of 95,1 x 144,3 mm. After the drying process the average dimensions of the sample were $91,3 \times 138,5 \mathrm{~mm}$. The values of the coefficients of variation obtained are lower than $1,3 \%$.

\section{The relationship between moisture content and longitudinal propagation velocity}

The linear relationships between the average values of wood moisture content and longitudinal propagation velocity in tests are shown in figure 4 for the three devices, and the maximum range of $\mathrm{MC}$ mean values runs from 35,5 to $9 \%$. A decrease in the moisture content clearly corresponds to an increase in the propagation velocity of the wave, with a strong correlation coefficient of 0,98 between the variables in Sylvatest 0,98 in Microsecond Timer, and 0,97 in the case of PLG. 


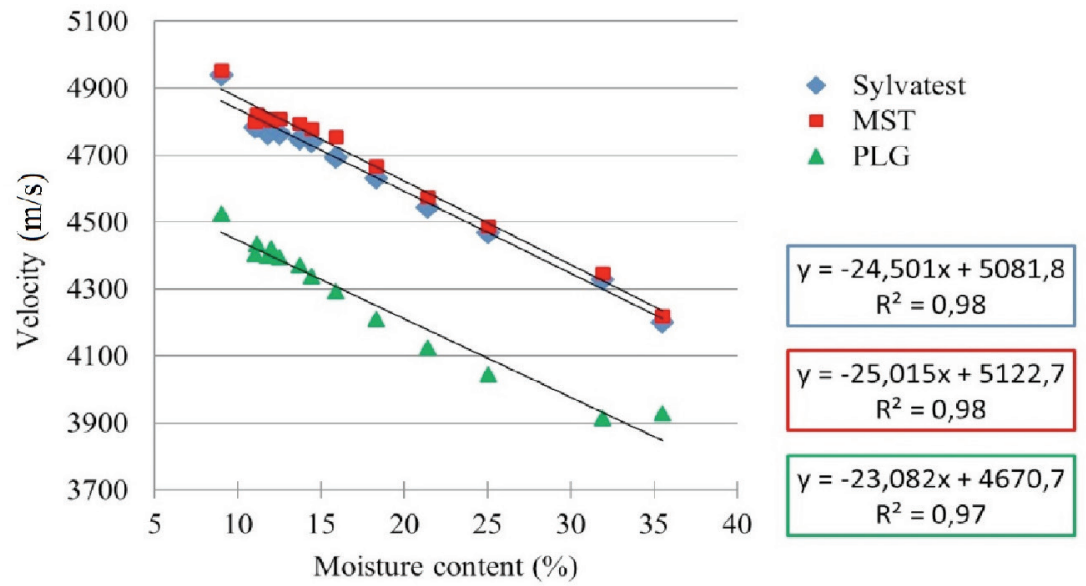

Figure 4. Linear relationship between the average values of propagation velocity and moisture content of the specimens for each set of equipment.

\section{Correction factor of the velocity for moisture content}

If the wave velocities through lumber obtained for two different moisture content values are compared, a good correlation coefficient between both velocities is obtained. As a decrease in moisture content $(\triangle M C)$ is related to an increase in wave velocity $(\Delta \mathrm{V})$ a constant value or coefficient can be obtained. This coefficient makes it possible to estimate the propagation velocity of a wave through lumber with a certain moisture content, determined from measurement of the propagation velocity at another moisture content. This coefficient was calculated for every piece according to equation 4 .

$$
\frac{\Delta V(m / s)}{\Delta M C(\%)}=\frac{V_{H 1}-V_{H 2}}{H 1-H 2}
$$

Where:

$\mathrm{V}_{\mathrm{H} 1}$ is the wave velocity corresponding to a moisture content $\mathrm{H} 1 \%$

$\mathrm{V}_{\mathrm{H} 2}$ is the wave velocity corresponding to a moisture content $\mathrm{H} 2 \%$

Different ranges of moisture content were analyzed, and different results were obtained for the three sets of equipment. The upper range analyzed was from 9,0 to $35,5 \%$.

Figure 5 shows the analyses corresponding to the velocities of an ultrasonic wave obtained with the Sylvatest Trio device and six ranges of moisture content, together with the relationship obtained. The best relationship corresponds to a range of moisture content from 11,8 to $21,4 \%$. 


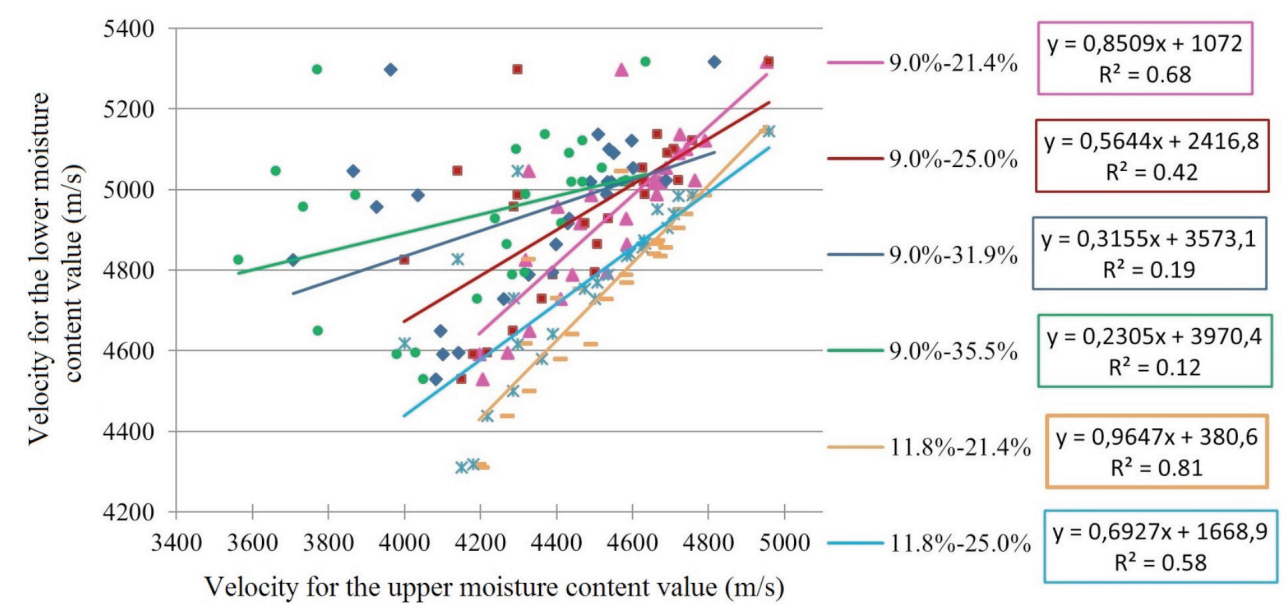

Figure 5. Linear relationship between the wave velocity values (V) for six ranges of moisture content. (Equipment: Sylvatest)

Based on the best relationship obtained for different ranges of moisture content (from 11,8 to 21,4 \%), wave velocity values obtained with the three devices for these moisture content levels were compared.

From the values of table 1 and equation 4, a decrease in velocity for each percentage point of moisture content can be calculated according to equations 5 and 6 :

$$
\frac{\Delta V}{\Delta M C}=\frac{V_{H 1}-V_{H 2}}{H 1-H 2}=\frac{4764,4-4544,2}{21,4-11,8}=22,94
$$

$$
\frac{22,94}{4764,4} * 100=48 \%
$$

So, for values of wood moisture content from $11,8 \%$ to $21,4 \%$ a decrease in velocity of $22,94 \mathrm{~m} / \mathrm{s}$ for each percentage point of moisture content increase can be estimated. This value represents a $48 \%$ decrease in velocity for each percentage point of moisture content increase. Therefore 0,48 is the correction factor of velocity in the said range of moisture content.

The same comparison between the wave velocities through the lumber in the same range of moisture content values are shown in figure 6 (for MST) and figure 7 (for PLG). 


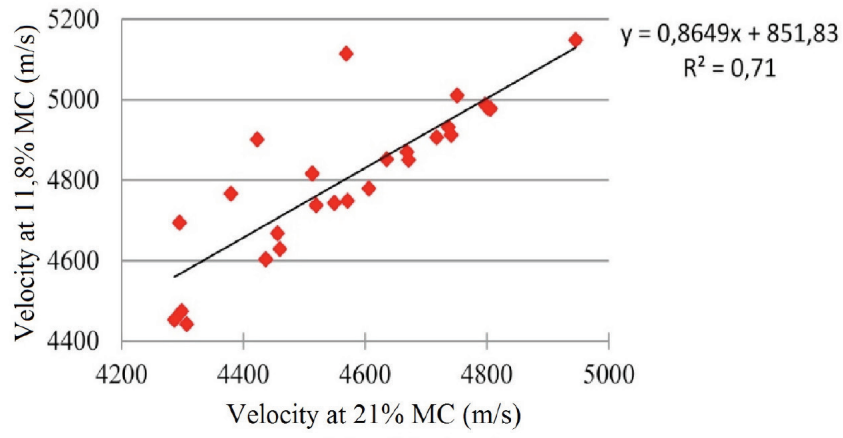

Figure 6. Relationship between propagation velocities under two different levels of moisture content. (Equipment: MST)

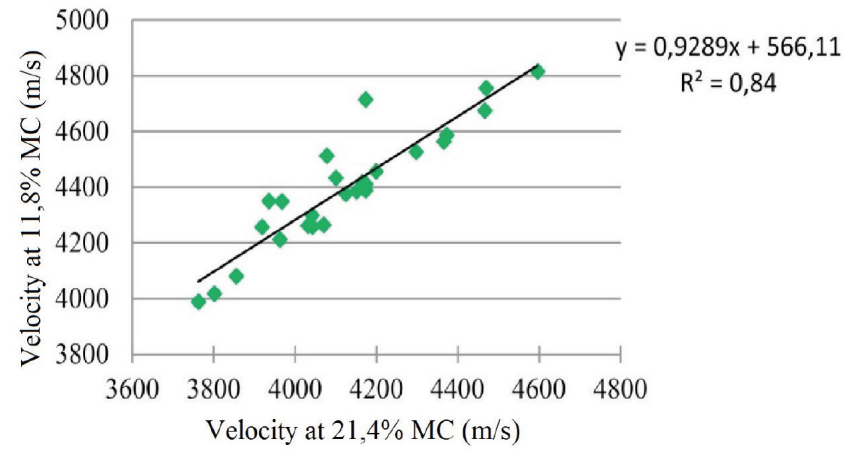

Figure 7. Relationship between propagation velocities under two different levels of moisture content.

(Equipment: PLG)

In the same way, it can be concluded that there is a decrease in the stress wave velocity of $24,37 \mathrm{~m} / \mathrm{s}$ for each percentage point of moisture content increase for the MST equipment. This corresponds to a decrease of $0,50 \%$ in velocity for each percentage point of moisture content increase.

And for the PLG a decrease in velocity of $28,42 \mathrm{~m} / \mathrm{s}$ is observed for each percentage point of moisture content increase and, therefore, the value of the constant stands at $0,65 \%$.

Other ranges of moisture content were analyzed, and the correction factor calculated shows no significant differences between moisture content ranges depending on the equipment (Table 2). 
Table 2. Correction factors and $\mathrm{R}^{2}$ for each range of moisture content and equipment.

\begin{tabular}{|c|c|c|c|c|c|c|}
\hline \multirow{2}{*}{$\begin{array}{c}\text { MC Range } \\
(\%)\end{array}$} & \multicolumn{2}{|c|}{ SYL } & \multicolumn{2}{|c|}{ MST } & \multicolumn{2}{|c|}{ PLG } \\
\cline { 2 - 7 } & $\mathrm{R}^{2}$ & $\begin{array}{c}\text { Correction } \\
\text { factor }\end{array}$ & $\mathrm{R}^{2}$ & $\begin{array}{c}\text { Correction } \\
\text { factor }\end{array}$ & $\mathrm{R}^{2}$ & $\begin{array}{c}\text { Correction } \\
\text { factor }\end{array}$ \\
\hline $9-21,4$ & 0,68 & 0,64 & 0,66 & 0,61 & 0,80 & 0,71 \\
\hline $9-25$ & 0,42 & 0,59 & 0,37 & 0,58 & 0,51 & 0,66 \\
\hline $9-31,9$ & 0,19 & 0,54 & 0,20 & 0,53 & 0,24 & 0,58 \\
\hline $9-35,5$ & 0,12 & 0,56 & 0,17 & 0,56 & 0,12 & 0,61 \\
\hline $11,8-21,4$ & 0,81 & 0,48 & 0,71 & 0,50 & 0,84 & 0,65 \\
\hline $11,8-25$ & 0,58 & 0,47 & 0,41 & 0,50 & 0,54 & 0,61 \\
\hline
\end{tabular}

\section{CONCLUSIONS}

The propagation velocity of ultrasonic and stress waves shows a strong linear dependence on moisture content for large cross-section Spanish Scots pine wood. The coefficient of correlation obtained in the range of moisture content values below the fiber saturation point stands at 0,98 for wave-based techniques (Sylvatest and MST) and 0,97 for techniques based on vibration (PLG).

A correction factor of the velocity by the moisture content has been defined in terms of a percentage of velocity increase for each percentage point of moisture content decrease. The best relationships observed are those obtained in the range of moisture content from 11,8 to $21,4 \%$.

The correction factor obtained for large cross-section Spanish Scots pine wood and a moisture content range from 11,8 to $21,4 \%$ reflects a decrease of $0,48 \%$ in ultrasound wave velocity for each percentage point of moisture content increase. In the case of stress wave this rate is $0,50 \%$, while for vibration velocity it is $0,65 \%$.

\section{ACKNOWLEDGEMENTS}

Ministry of Education and Science, BIA2006-14272: "Influence of some defects on the mechanical properties of gross cross section timber for structural use: drying fissures and sawn defects". The research was performed in the Timber Laboratory of the National Institute for Agricultural Research of Spain (INIA-CIFOR). 


\section{REFERENCES}

Arriaga, F.; Íñiguez, G.; Fernández-Golfín, J.I.; Esteban, M. 2005. Aplicación de la técnica de ultrasonidos en la clasificación de la madera de pino radiata (Pinus radiata D.Don) en piezas de gran escuadría para uso estructural. Actas de las I Jornadas de Investigación en Construcción. Madrid. 2-4 junio 2005. Instituto de Ciencias de las Construcción "Eduardo Torroja". Consejo Superior de Investigaciones Científicas. p. 403-415.

Arriaga, F.; Íñiguez, G.; Esteban, M.; Fernández-Golfín, J.I. 2006. Structural Tali timber (Erythrophleum ivorense A. Chev., Erythrophleum suaveolens Brenan.): Assessment of strength and stiffness properties using visual and ultrasonic methods. Holz als Roh- und Werkstoff 64:357-362.

Bucur, V. 2006. Acoustics of Wood. $2^{\text {nd }}$ Edition. Springer Series in Wood Science Springer, Berlin, Heidelberg, Germany. 455 p.

Cornejo, J.; Baettig, R. 2009. Evolución del módulo de elasticidad longitudinal entre $10^{\circ} \mathrm{C}$ y $100^{\circ} \mathrm{C}$ en piezas de Pinus radiata usando una técnica de evaluación no destructiva. Maderas Ciencia y Tecnologia 11(2):153-160.

Cui, Y.Y., Zhang, H.J.; Sheng, W. 2005. The study on stress grading for Pinus sylvestris var. mongolica based on transverse vibration method. Forestry Machinery and Woodworking Equipment 33(10): 24-28.

De La Mata, J. 2011. Influence of wood moisture content in the evaluation of the mechanical properties of Scots pine by non destructive techniques. Final Project Degree. ETSI Montes. Universidad Politécnica de Madrid.

EN 13183-2: 2002. Moisture content of a piece of sawn timber. Part 2: estimation by electrical resistance method.

Esteban, M.; Argüelles, R.; Arriaga, F.; Íñiguez, G.; Bobadilla, I. 2007. Current state of research on structural timber in Spain. Informes de la Construcción 59(506):15-27.

Gonçalves, R.; Leme Da Costa, O.A. 2008. Influence of moisture content on longitudinal, radial, and tangential ultrasonic velocity for two Brazilian wood species. Wood and Fiber Science 40(4):580-586.

Görlacher, R. 1990. Klassifizierung von Brettschichtholzlamellen durch messing von Longitudinalschwingungen. PhD Thesis. Universität Fridericiana zu Karlsruhe.

Hermoso, E.; Fernández-Golfín, J.I.; Díez, M.R.; Mier, R. 2007. Aplicación de los ultrasonidos a la evaluación de las propiedades mecánicas de la madera en rollo de pequeño diámetro (Ultrasound application to evaluation of small round timber mechanical properties). Informes de la Construcción 59(506):87-95.

Íñiguez, G. 2007. Clasificación mediante técnicas no destructivas y evaluación de las propiedades mecánicas de la madera aserrada de coníferas de gran escuadría para uso estructural. (Grading by non destructive techniques and assessment of the mechanical properties of large cross section coniferous sawn timber for structural use). Ph.D. Thesis. Universidad Politécnica de Madrid, Madrid, Spain.

Kang, H.; Booker, R.E. 2002. Variation of stress wave velocity with MC and temperature. Wood Science and Technology 36:41-54. 
Mishiro, A. 1995. Ultrasonic velocity in wood and its moisture content. Effects of moisture content gradients on ultrasonic velocity in wood. Mokuzai Gakkaishi 41(6):1086-1092.

Oliveira, F.G.R.; Candian, M.; Lucchette, F.F.; Salgon, J.L.; Sales, A. 2005. A technical note on the relationship between ultrasonic velocity and moisture content of Brazilian hardwood (Goupia glabra). Building and Environment 40: 297-300.

Ross, R.; Pellerin, R. 1991. NDE of green material with stress wave: preliminary results using dimension lumber. Forest Products Journal 41(6):57-59.

Ross, R.; Pellerin, R. 1994. Nondestructive testing for assessing wood members in structures: A review. U.S. Department of Agriculture. Forest Products Laboratory. Technical Report: 70, Madison. 42 p.

Sakai, H.; Minamisawa, A.; Takagi, K. 1990. Effect of moisture content on ultrasonic velocity and attenuation in woods. Ultrasonics 28:382-385.

Sales, A.; Candian, M.; De Salles Cardin, V. 2011. Evaluation of the mechanical properties of Brazilian lumber (Goupia glabra) by non destructive techniques. Construction and Building Materials 25(3):1450-1454 .

Sandoz, J.L. 1989. Grading of construction timber by ultrasound. Wood Science and Technology 23: 95-108.

Sandoz, J.L. 1993. Moisture content and temperature effect on ultrasonic timber grading. Wood Science and Technology 27 (5): 373-380.

Simpson, W.T.; Wang, X. 2001. Relationship between longitudinal stress wave transit time and moisture content of lumber during kiln drying. Forest Products Journal 51(10):51-54.

UNE 56544: 2007. Clasificación visual de la madera aserrada para uso estructural. Madera de coníferas. (Visual grading of sawn timber for structural use. Coniferous timber)

Unterwieser, H.; Schickhofer, G. 2011. Influence of moisture content of wood on sound velocity and dynamic MOE of natural frequency- and ultrasonic runtime measurement. European Journal of Wood and Wood Products 69: 171-181.

Wang, X.; Chuang, S. 2000. Experimental data correction of the dynamic elastic moduli, velocity and density of solid wood as a function of moisture content above the fiber saturation point. Holzforschung 54: 309-314.

Wang, X.; Ross, R.J. 2002. Nondestructive evaluation of green materials - Recent research and development activities. Nondestructive Evaluation of Wood. Forest Products Society. Pellerin, R.F. and Ross. Madison, Wisconsin. Chap 10, p.149-171.

Wang, X.; Ross, R.J.; Mcclellan, M.; Barbour, R.J.; Erickson, J.R.; Forsman, J.W.; Mcginnis, G.D. 2000. Strength and stiffness assessment of standing trees using a non destructive stress wave technique. USDA Forest Service, Research Paper FPL-RP-585. Forest Products Laboratory. June 2000. 9 p.

Yin, Y.; Jiang, X.; Wang, L.; Bian, M. 2011. Predicting wood quality of green logs by resonance vibration and stress wave in plantation-grown Populus x euramericana. Forest Products Journal 61(2):136-142. 